\title{
New Combined Solution to Harness Wave Energy- Full Renewable Potential for Sustainable Electricity and Fresh Water Production ${ }^{+}$
}

\author{
Michael Henriksen ${ }^{1}$, Simon Davide Luigi Piccioni ${ }^{2}$ and Massimo Lai ${ }^{2, *}$ \\ 1 Wavepiston, 3000 Helsingør, Denmark \\ 2 Ener.Med., 09134 Cagliari, Italy \\ * Correspondence: massimo@enermed.it \\ † Presented at the Sustainable Places 2019 (SP 2019), Sardinia, Italy, 5-7 June 2019.
}

Published: 23 July 2019

\begin{abstract}
This paper is a first general dissemination of the H2020 Project Wave to Energy and Water (W2EW) started in January 2019. The joint vision of the W2EW consortium (Wavepiston, Ener.Med, Fiellberg, Vryhof) is to deliver a world-beating wave powered technology solution for electricity production and desalination. It relies on the innovative integration of wave energy and sea water desalination technologies, to produce zero-emission electricity and fresh water, with dynamic optimization of energy production and maximizing the available wave energy using fresh water as storage. The W2EW solution enables competitive cost of electricity and water. The present project is critical to demonstrate the W2EW solution in a real-life environment, to reduce the risk profile of the solution and to build the market to pave the way for broad market roll-out. The scope of the paper is to introduce the project W2EW and its expected results to a broader audience.
\end{abstract}

Keywords: wave energy; renewable energy; water desalination; zero-emission electricity; smart grid; smart island; island sustainability; decarbonising islands

\section{Introduction}

The theoretical ocean wave energy potential is estimated to be 29,500 TWh/year [1] (page 15), which could contribute to decarbonizing the energy system, expanding the water supply through desalination and creating a new industry with export opportunities worldwide. However, this opportunity remains underexplored due to remaining technological, market, environmental and social challenges. Ocean Energy Europe estimates that $100 \mathrm{GW}$ of ocean energy can be installed in Europe by 2050 [2]. According to a JRC report of EU commission the direct EU economic impact of drought events in the past 30 years can be estimated at a minimum of $€ 100 \mathrm{BN}$ [3]. Nearly half of the world's population, $3.6 \mathrm{Bn}$ people, are experiencing water scarcity already now. At the same time the global demand for water increases at a rate of $1 \%$ per year [4]. These conditions give a unique opportunity for strong industrial cooperation towards the deployment of solutions to address the twin challenges of energy and fresh water shortage. Leveraging on a strong consortium vision, expertise and technologies, the W2EW project aims to deliver a world beating wave powered technology solution-W2EW solution - to the market. The solution relies on the integration of wave energy and water desalination technologies, to produce zero-emission electricity and fresh water. The main goal of this project is to integrate the partners' technologies, demonstrate the combined solution, and build the market to pave the way for broad market roll-out. After successful test the consortium plans to roll out the W2EW solution on off grid small-scale energy and water production, that is introduced in the following pages of this paper, in islands and isolated coastal communities. After 2025 the consortium W2EW intend to extend the customer base of the W2EW solution to the 
large-scale utilities for production of renewable energy and/or water desalination, to be an alternative and/or to operate in synergy with offshore wind and solar PV.

\section{Concept, Methodology and State of Development}

The W2EW concept (Figure 1) relies on the innovative integration of wave energy with desalination technologies to produce zero-emission electricity and fresh water at a competitive cost and enabling the management of the wave energy intermittency through water storage.

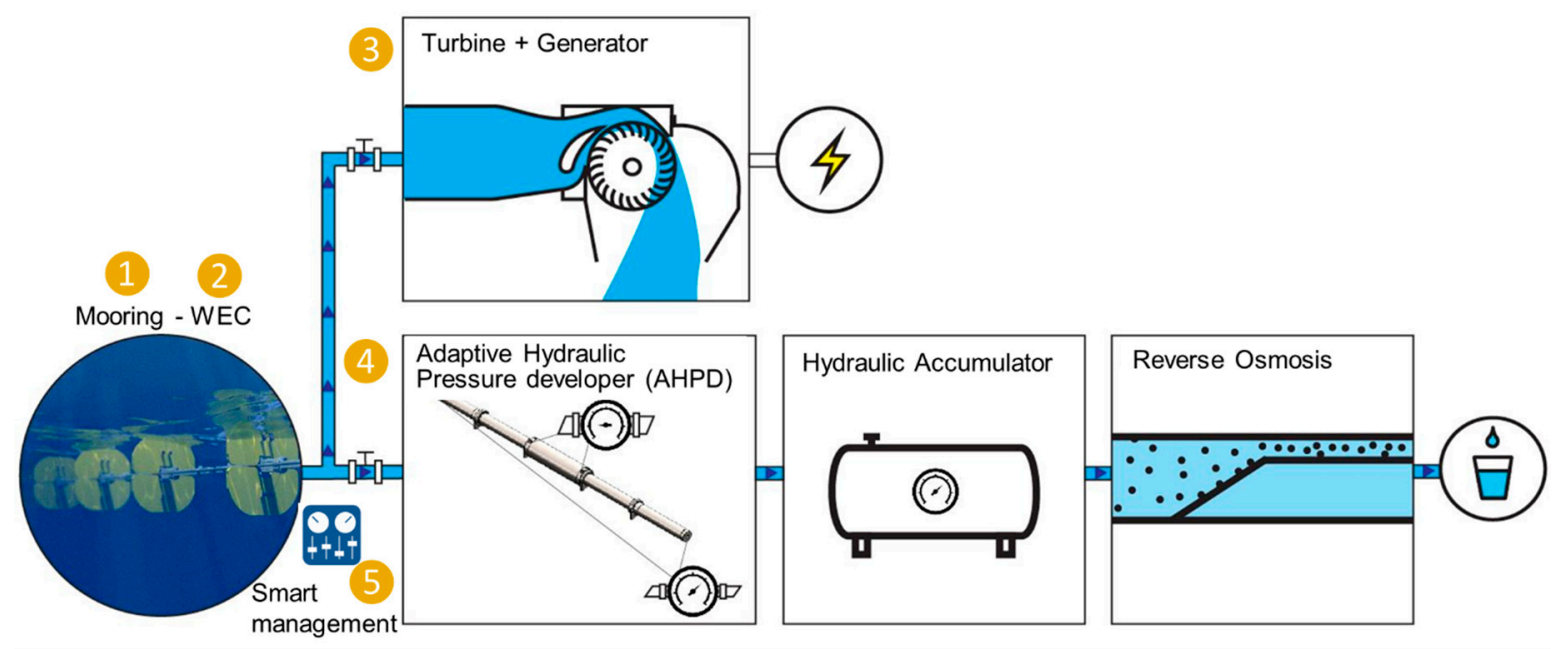

Figure 1. W2EW concept and technologies integration.

The W2EW solution takes advantage of the efficient combination of the WEC with a tailored mooring system (1-2) (Figure 2). The waves movement is converted into pressurized water. It can go to the land-based turbine generator for conversion to electricity (3) and/or to the plant for seawater desalination (for fresh water production, 4). Due to the intermittency of the wave energy, a flow control system - using valves, which are controlled by an electrical signal-will manage the electricity and/or water production in real-time, to maximize the system performance (5). This management is performed based on information on the consumption and production from other sources, as well as storage capacity.

The low cost, good energy conversion efficiency and survivability of the WEC has been tested and validated for scale models (Figure 3) in a wave tank and under real sea conditions. Between 2010 and 2018, 3 development projects were undertaken:

- A 1:30 prototype was tested in a wave tank at the University of Aalborg in irregular waves at 5 different wave states. The experimental results confirmed the system potential (energy calculations validated by Niras A/S, a large multidisciplinary consultancy company) and helped to define the strategy for further development;

- A 1:9 prototype was tested offshore, at the Nissum Bredning test centre, (limited fetch sea trial, i.e. small-scale waves). The system worked flawlessly and the 8 mounted energy collectors (ECs) maintained their efficiency during the test period without maintenance despite heavy biofouling and millions of wave cycles.

- In 2014, the consortium Vryhof, Fiellberg, the Technical University of Denmark and Wavepiston won a Danish national grant (ForskEL) to undertake a prototype project of the system in scale $1: 2$ testing in an open ocean environment (full fetch sea trial, in a very exposed wave climate). A version 1 of the prototype was installed in the North Sea at the DanWEC test site in August 2015. A version 2 of the prototype was installed in May 2017. A version 3 was installed in November 2018. The prototype has survived $7 \mathrm{~m}$ significant wave height, confirming the energy conversion efficiency and cost level of a commercial system. No adverse environmental impacts have been observed. 

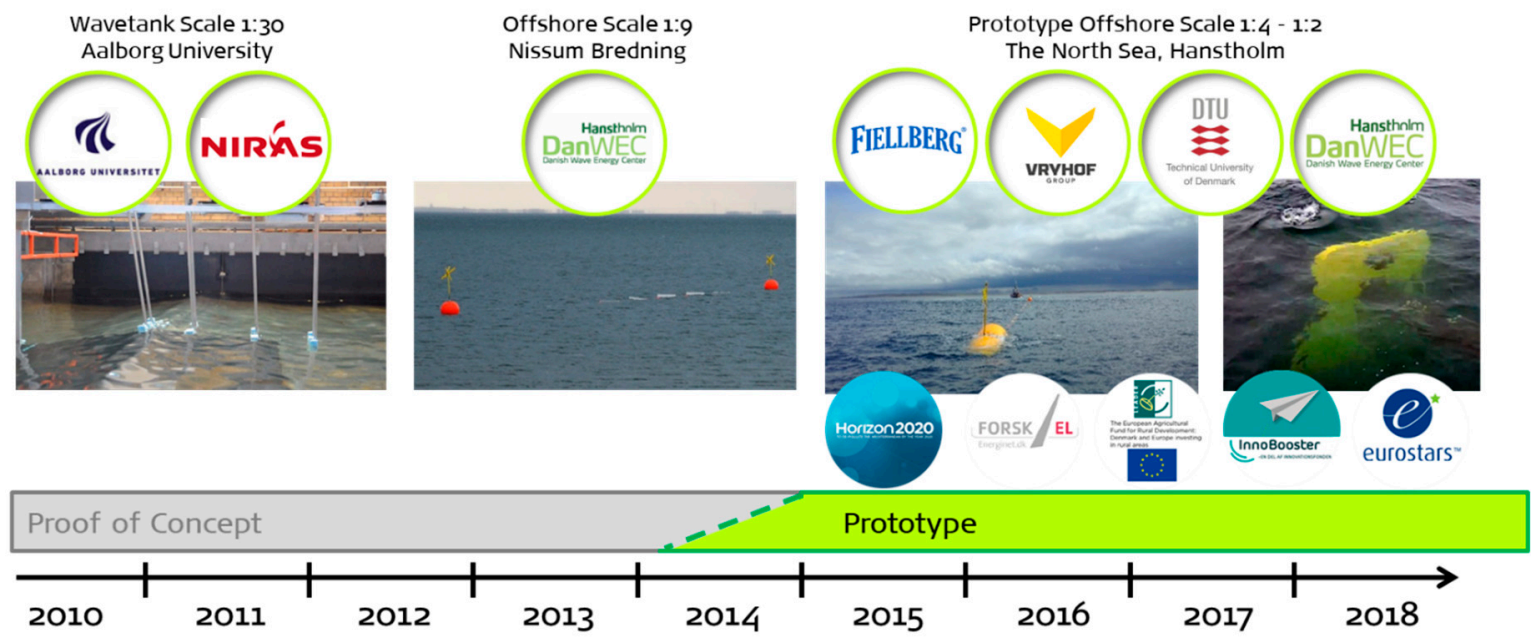

Figure 2. Technology validation.

\subsection{ForskEL Project (1:2 Scale Prototype Test in the North Sea)}

\subsubsection{Short Description}

The project covers a demonstration of the Wavepiston wave energy concept. Numerical tools for estimation of structural design loads and absorbed power for the concept were developed, together with a tool to model the motion of the complete string structure. A 1:2 scale installation was designed, built and installed in the North Sea. With several iterations made on the detailed design during the tests conducted at sea, the reliability and power performance of the concept were improved considerably. The power output from the installation confirmed the predictions of the numerical tools. A business analysis was carried out using the numerical tools and wave data for reference sites selected according to the large attention from potential customers to the concept. The business analysis supports a viable market launch plan for Wavepiston.

\subsubsection{Project Objectives}

Three project objectives were defined in the application:

- $\quad$ Objective 1: Development of a refined hydrodynamic model.

- Objective 2: Construction and test of a small-scale demonstration structure.

- $\quad$ Objective 3: Determination of the power production efficiency.

\subsubsection{Project Results}

The project results are here summarised for the three different project objectives listed in 3.1.2.

- Results for Objective 1: The key results for Objective 1 are the Wavepiston load and energy tools. These tools allow both design loads and annual power production to be calculated for any site where the water depth and records for significant wave height, peak period and wave direction are available. The tool calculates the power based on an optimum or specified hydraulic pressure in the delivery pipe connected to each EC. The captured energy can be used in the business case for both electricity generation and desalination of pressurised water through reverse osmosis.

- Results for Objective 2: Detailed design and test of four consecutive versions of the energy collector ECs (Figure 4) for the Wavepiston system; detailed design and test of two consecutive versions of the buoys at each end of the string; detailed design of string assembly in three different versions; invention and detailed design of telescopic pump solution in the ECs; verification of the power performance simulated with the Wavepiston energy tool Construction and test of a small-scale demonstration structure. 


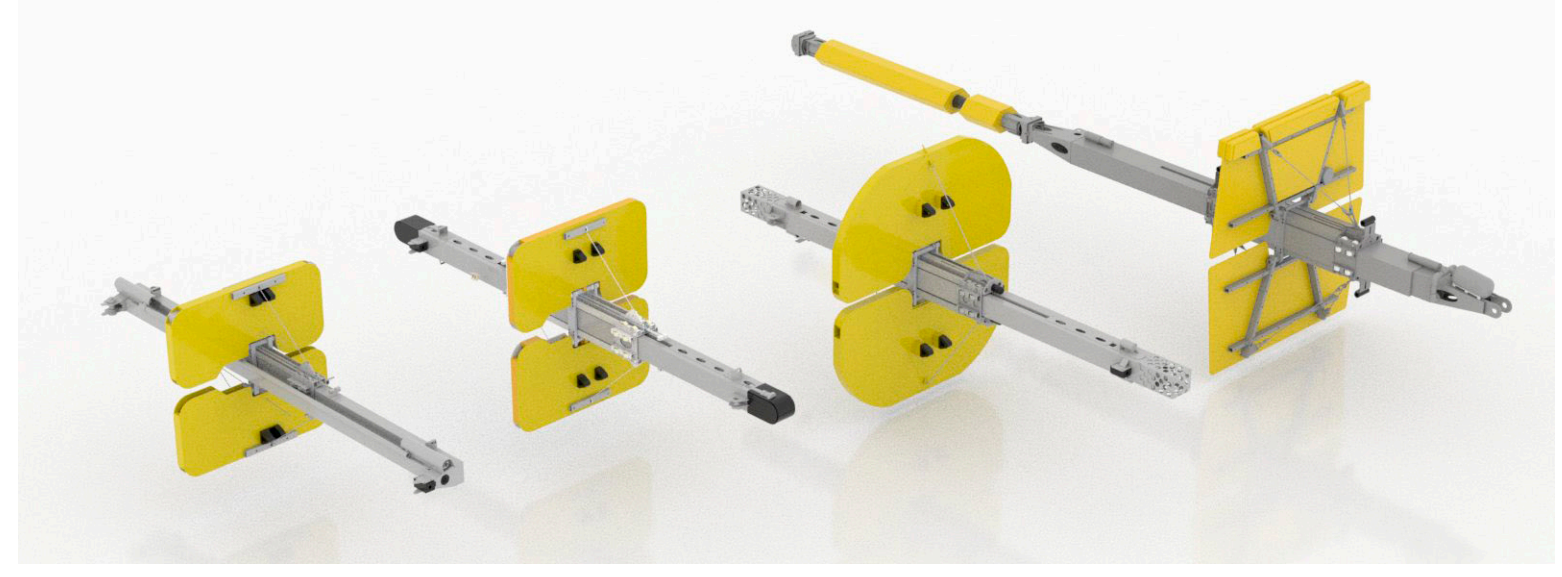

Figure 3. Versions of the energy collector (EC) developed in the ForskEL project.

- Results for Objective 3: the Wavepiston Energy Tool supports business case analysis by calculating the annual energy production AEP or amounts of desalinated water according to wave data and water depth from any type of site.

The levelised cost of energy (LCoE) model developed in the project is a key result. It calculates yield based on the results from the Wavepiston energy tool. The CAPEX and OPEX in the LCoE is based on simple scaling of the financial figures from the present project taking account of the physical scale and the scale of the manufactured and installed volume. As such, the financial account for the different project activities is also a key result.

Typical values for the LCoE from the business case analysis are in the range of $0.2 \mathrm{EUR} / \mathrm{kWh}$ for the first smaller installations in isolated communities. Over time the potential is estimated to be $0.03 \mathrm{EUR} / \mathrm{kWh}$ for very large installations.

The business cases analysed for the different potential sites suggest that the desalination of water is an important market for the technology.

More details and videos can be found under the Supplementary Material.

\subsubsection{Utilization of Project Results}

The positive outcome of the tests in Hanstholm and the business analysis under the project are considered as key factors for the European Commission granting financial support to further two demonstration projects (Figures 4 and 5) at full scale by the end of the project period: 1. Competitive Wave Energy on Islands, SME Instrument under Horizon 2020 project at the PLOCAN facility, Gran Canaria 2. Wave to Energy and Water, Fast Track to Innovation under Horizon 2020 project at Isola Piana, Sardinia. 
PLOCAN, Gran Canaria
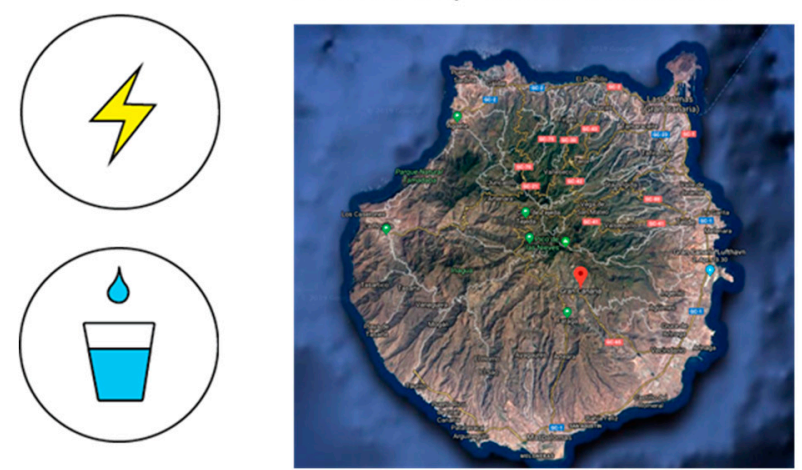
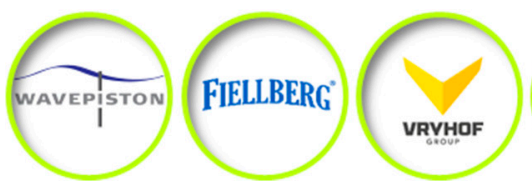

Figure 4. Sites of demonstration phase projects.

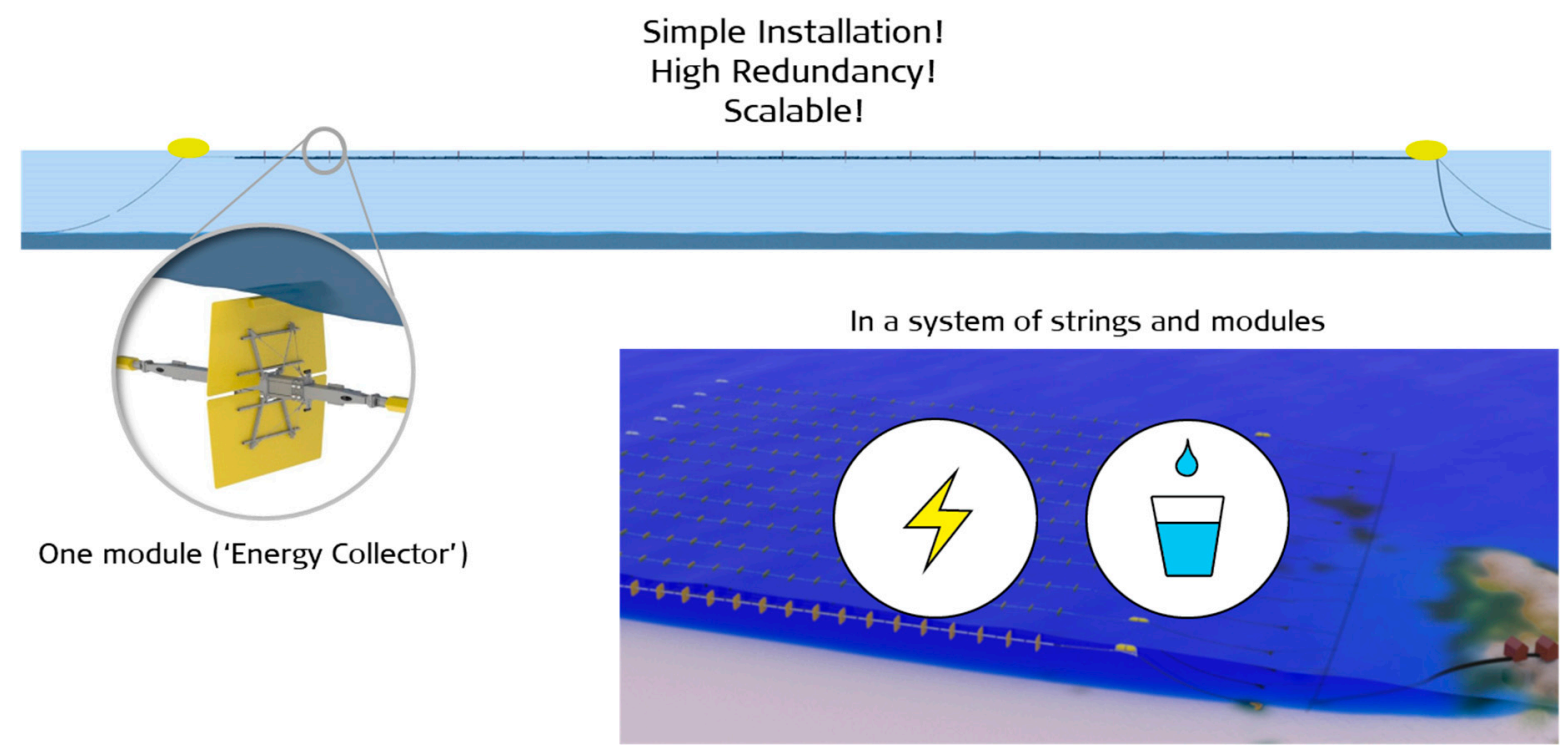

Figure 5. The W2EW Concept.

\subsection{W2EW Project-Isola Piana (1:1 Scale)}

\subsubsection{Data on Location}

Isola Piana is a small privately-run island with holiday apartments and a marina, located in the South-West coast of Sardinia, between the Island of S. Pietro and the Sardinia island. In the following Table 1 are reported the main characteristic dimensional data of the location. 
Table 1. Dimensional data input.

\begin{tabular}{cccc}
\hline Description & U.M. & Quantity & Notes \\
\hline Area & $\mathrm{km}^{2}$ & 0.21 & \\
Coastline & $\mathrm{km}$ & 1.8 & \\
Max altitude point & $\mathrm{M}$ & 1.9 & \\
Residential buildings & $\mathrm{n}$. & 180 & \\
Peak of population & person & 400 & In summer season \\
Estimated energy consumption & $\mathrm{MWh}$ & 650 & \\
Estimated water consumption & $\mathrm{m}^{3}$ & 15,000 & \\
\hline
\end{tabular}

\subsubsection{Main Project Data}

In the following Table 2 are reported the main characteristic dimensional data of the project W2EW.

Table 2. Dimensional data input.

\begin{tabular}{cccc}
\hline Description & U.M. & Quantity & Notes \\
\hline Project costs & M€ & 4.9 \\
Project duration & Months & 32 \\
Energy peak power generator & $\mathrm{kW}$ & 150 \\
Estimated energy production & $\mathrm{MWh}$ & 280 \\
Estimated fresh water production & $\mathrm{m}^{3}$ & 15,000 \\
Number of strings & $\mathrm{n}$. & 1 \\
Length of string & $\mathrm{m}$ & 187 \\
Distance to shore & $\mathrm{m}$ & $300-500$ \\
\hline
\end{tabular}

\subsubsection{Short Description}

The project consists in the implementation of a smart grid off-grid model solution by the construction of a demonstration full-scale prototype (Figure 6) expected to deliver $150 \mathrm{~kW}$ of energy peak-power producing $280,000 \mathrm{kWh}$ and $15,000 \mathrm{~m}^{3}$ of fresh water per year.

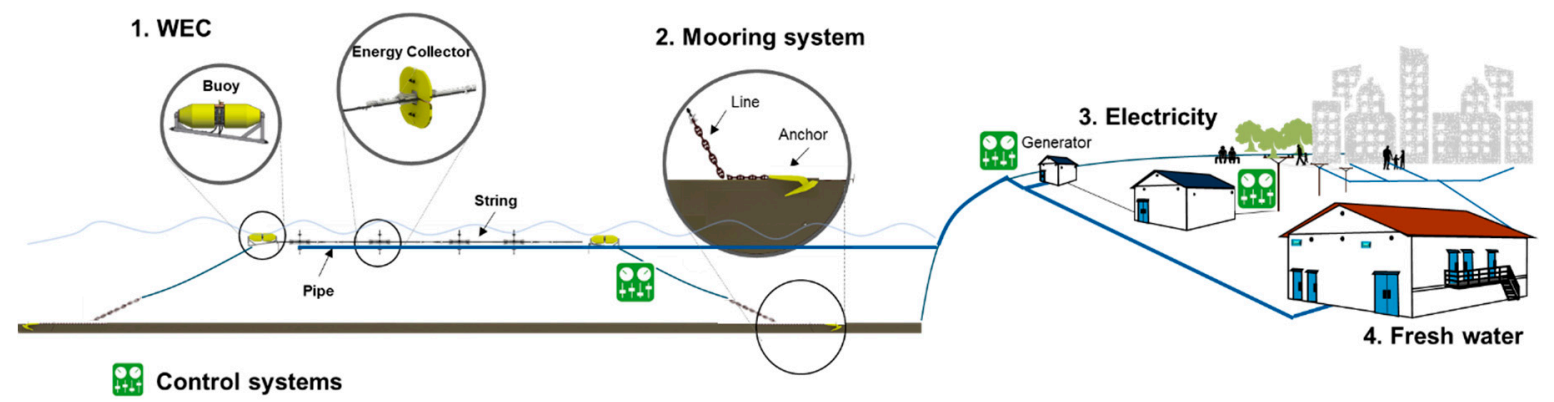

Figure 6. Demonstration W2EW smart grid model.

The grid infrastructure is private and is not connected to the regional distribution grid. Isola Piana has a low-medium wave power climate, which will enable to demonstrate the economic feasibility of the W2EW solution even in modest EU wave climates, under different sea conditions, thereby building market confidence and facilitating the market replication for other places/climates.

A key novelty behind W2EW solution is the Ener.Med's smart management platform-TECHUS, which works as a control hub that oversees the execution of each control unit (WEC-, flow- and electricity- control systems). This system makes possible to efficiently manage energy and water production to meet, in real time, the consumption needs. This platform provides guidance on finding and capturing the most compelling savings opportunities, ultimately allowing to optimize 
production/consumption and to maximize the use of energy using fresh water as storage. It is possible in all situations, and without any energy conversion loss, to control an optimal conversion between electricity and fresh water depending on consumption and storage possibilities enabling the most economical generation operations.

\subsubsection{Project Objectives}

The main objective of this innovation project is the integration of the different technologies to fill a gap in the wave energy and water desalination market and exploit the combined resource potential in Europe. The WEC system will be upscaled to reach a 1:1 scale and the four technologies will be integrated. Upon the demonstration in a real-life environment of the full-scale prototype, qualification and implementation of design for manufacturing and assembly, planned under the W2EW project, the proposed solution will reach the commercial readiness.

\subsubsection{Project Expected Results}

To accomplish the main project objective and overcome the existing barriers, thereby unlocking the market potential of a combined solution for zero-emissions electricity and water production the approach will be the following:

- Integrate and demonstrate a combined solution for zero-emissions electricity and water production, which will make it attractive to a wider range of customers;

- Reduce costs through the update of the components design as well as several sequential design cycles.

- Staged integration and deployment, where testing is carried out both at the components and system level, before final system integration and deployment, to reduce the risks of malfunctioning and ensure optimal integration;

- Demonstration at a European island of a full-scale prototype during 18 months in real life operational conditions to maximize the installation efforts and to build the required market confidence and awareness.

- Collection of solid a basis to advertise the economic and environmental benefits, critical to convince stakeholders of the added value of offered by the W2EW solution, remove negative perceptions related potential negative environmental impacts and to foster the development of commercial projects;

- Collection of data for life cycle assessment and qualification, to offer customers a demonstration of "fitness for service", which is critical to speed up the permitting process of new installations and to reduce the risk profile and insurance costs;

- Strengthen market and regulatory intelligence.

\section{The W2EW Consortium}

The W2EW consortium is composed by:

- Wavepiston (DK, SME) has developed the WEC technology;

- Vryhof (NL, LE) - a world leader in large anchoring and mooring solutions;

- Fiellberg (FI, SME) - a manufacturer and supplier of customized hydraulic pumps technology, specialized in demanding marine, offshore and subsea applications.

- $\quad$ Ener.Med (IT, SME) - a supplier of electricity and developer of smart grid projects for the Italian market. The company has an extensive expertise in the energy planning, electrical energy market and on the implementation of installations for renewable energy production and smart management platforms.

\section{Conclusions}

By achieving the objectives and the expected results of the W2EW project, we will be able to confirm that the W2EW Solution could be considered an ideal solution for the implementation of 
smart grid model development based on zero emission energy and water production especially for island sustainability, and a valid alternative to or integration with offshore wind and solar PV.

Supplementary Materials: Pecher, A.; Kofoed, J.P.; Angelelli, E. Experimental Study on the Wavepiston Wave Energy Converter, Aalborg. University: Aalborg, Denmark, 1 April 2010. Wavepiston MK I test at Nissum Bredning, Final Report, September 2013. Wavepiston-Next Generation Wave Power, ForskEL-project no. 2015-1-12275, Final Report, March 2019. https://vimeo.com/307470243; https://vimeo.com/314432460. More information, documents and videos are available online at http://www.wavepiston.dk.

Funding: The project W2EW has received funding from the European Union's Horizon 2020 research and innovation programme under grant agreement No. 831041.

Conflicts of Interest: The authors are involved in the design, development and execution of the project, including collection, analysis and management of data.

\section{References}

1. IRENA. Wave Energy Technology Brief 4. June 2014. Available online: https://www.irena.org/ documentdownloads/publications/wave-energy_v4_web.pdf (accessed on 10 April 2019).

2. Ocean Energy Forum. Ocean Energy Strategic Roadmap 2016, Building Ocean Energy for Europe. 2016. Available online: https://webgate.ec.europa.eu/maritimeforum/sites/maritimeforum/files/OceanEnergy Forum_Roadmap_Online_Version_08Nov2016.pdf (accessed on 1 November 2016).

3. Spinoni, J.; Naumann, G.; Vogt, J.; Barbosa, P. Meteorological Droughts in Europe: Events and Impacts - Past Trends and Future Projections; Publications Office of the European Union: Luxembourg, 2016.

4. United Nations World Water Assessment Programme. The United Nations World Water Development Report 2018: Nature-Based Solutions for Water. 2018. Available online: https://en.wikipedia.org/wiki/ World_Water_Assessment_Programme (accessed on 23 July 2019).

(C) 2019 by the authors. Licensee MDPI, Basel, Switzerland. This article is an open access article distributed under the terms and conditions of the Creative Commons Attribution (CC BY) license (http://creativecommons.org/licenses/by/4.0/). 